\title{
Sex Differences in Delaying Family: Effects on Job and Life Satisfaction
}

\author{
Joshua Doerner \\ Southern Illinois University \\ Carbondale, Carbondale, USA
}

\author{
Joel T. Nadler \\ Southern Illinois University \\ Edwardsville, Edwardsville, UAS
}

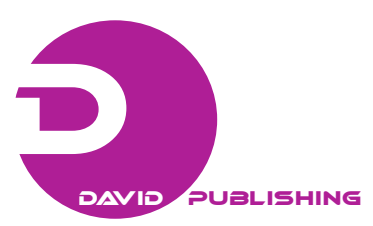

\begin{abstract}
Individuals in the workplace can have a difficult time advancing both career and family, and this remains especially true for women. The decision to forego or delay a relationship in favor of advancement at work can have a detrimental impact on satisfaction. A national sample $(N=3504)$ was examined for sex differences in delaying relationships and the resulting impact on life and job satisfaction. An interaction was found between sex and delaying relationship commitments in relation to pay satisfaction. Men who had not delayed committing to a relationship were significantly more satisfied with pay than those who delayed. However, women did not show this difference. Men and women who delayed a relationship displayed significantly lower levels of life satisfaction. Women also reported lower earnings and more family stress, but also reported higher levels of job satisfaction. Overall, delay of marriage and family can lead a decrease in pay satisfaction, life and family satisfaction and an increase in stress.
\end{abstract}

Keywords: gender, job satisfaction, sex roles, work-family conflict

\section{Introduction}

The reasons why people work include as a means to survive, provide for family, fulfill financial obligations and carry out a desire to achieve. Many traditional jobs, combined with inflexible employment policies, do not coincide well with family obligations. The conflict between work and family can be a major source of stress and is often cited as a larger concern by women compared to men (Vagg, Spielberger, \& Wasala, 2002). Women tend to make significantly lower wages compared to men for the same work (Morgan, 2008) and women are not provided with similar advancement opportunities compared to men (Escriche, 2007). One of the suspected barriers to women's advancement and greater wage attainment is the conflict between work and family (Drobnic, Blossfeld, \& Rohwer, 1999). Men and women experience different career and pay experiences in the workplace and the importance of maintaining a balanced family life is more often a stressor in women (Hough, 1987). Both the roles of motherhood and larger numbers of children negatively affect women's career success, but do not negatively impact men (Kaufman \& Uhlenberg, 2000). Finally, women, citing family concerns, are less likely to move or travel for their careers further hampering advancement (Baldridge, Eddleston, \& Viega, 2006). Women are more concerned and affected by issues of work-family balance and thus women's career decisions that affect this balance may have a stronger impact on women's

Joshua Doerner, Department of Psychology, Southern Illinois University Carbondale.

Joel T. Nadler, Ph.D., assistant professor, Department of Psychology, Southern Illinois University Edwardsville.

Meghan R. Lowery, Ph.D., Director of Organizational Development Consulting, Psychological Associates. 
satisfaction levels compared to men.

The purpose of this study is to determine if the choice to delay romantic relationships and starting a family differentially affects men's and women's life and job satisfaction as well as perceptions of work-family stress. Women are still the primary caregivers of children and do the majority of the housework even in dual-earner households (Bond, Thompson, Galinsky, \& Prottas, 2002). Sewell, Hauser, and Wolf (1980) found that having family negatively impacted women's careers but not men's. A qualitative analysis of women's careers found that women often choose careers, which allow greater flexibility in work family conflict (Whitmarsh, Brown, Cooper, Hawkins-Rodgers, \& Wentworth, 2007). Whitmarsh et al. (2007) found that women plan pregnancy and other family events around work schedules, and in turn, report difficulties in trying to maintain both family and career responsibilities. Work-life balance is possible and some work places have recognized the importance of providing work flexibility, but some organizations have not redesigned their infrastructure to make this work-life balance more manageable for those who desire both a career and a family.

Hoffnung (2004) found that managers who rated themselves higher in work-life balance were rated higher in career advancement potential compared to those who rated themselves low in work-life balance, indicating that employees may experience more advancement when they do not feel their work and family dynamic is out of balance. Alternatively, this may mean that those who experience advancement do so, because they do not experience work-life conflict. Reflecting the latter, Hoffnung (2004) also found that career-oriented women are more likely to delay relationships or children in order to advance their careers. Buddhapriya (2009) found in a population of female Indian professionals that the most reported barrier for advancement into senior positions was commitment to family responsibilities. Although these results were the same for men and women, women professionals reported a greater desire for employers to be more supportive of non-work commitments and life-balance issues compared to men (Buddhapriya, 2009). Buddhapriva suggests that organizations could make the work-life balance more manageable for employees by restructuring scheduling, providing childcare support or designing programs aimed at promoting wellness for working parents. Ford, Heinen, and Langkamer (2007) conducted a meta-analysis that found in order for organizations to maximize the satisfaction of its employees, the organization needs to take into consideration the influences that occur outside of the organization, such as family.

Typically, women are more likely to perceive workplace pressure to make a choice between career and family and tend to prefer close mentoring relationships at work (Nielsen, Yarker, Randall, \& Munir, 2009). This is partly due to traditional gender roles, such as women being more social (Eagly, 1987). Balancing career and family can cause stress and anxiety, particularly for women (Ford, Heinen, \& Langkamer, 2007). Women typically experience more exhaustion as a result of struggling to find work-life balance compared to men (Canivet et al., 2010). Women benefit when their significant, other demonstrates a willingness to assist in sharing household chores and familial obligations (Canivet et al., 2010). Though more egalitarian partnerships are becoming more popular, this balance of work and family is still more of a burden for women in the labor force than for their male counterparts (Bond et al., 2002; Presser, 1994). Women are more likely to spend a greater amount of time in both work and family roles resulting in higher stress level for women compared to men (Galakanis, Salikas, Kallia, Kargianni, \& Karela, 2009).

One factor to consider when weighing the pros and cons of starting a family is satisfaction in and across the different domains of one's life. How one is satisfied with their jobs is usually an indicator of how 
permanent of a position it will become (Perrachione, Rosser, \& Peterson, 2008). Researches have shown that women tend to exhibit higher levels of job satisfaction than men (Buchanan, 2005). The paradox of the contented female worker states that despite lower pay and lesser advancement opportunities, women tend to be more satisfied than men are in their jobs (Phelan, 1994). Phelan (1994) attempted to explain this paradox by suggesting that when women report higher satisfaction with work and pay, their responses are a reflection of derived satisfaction from other sources than a paycheck. Beutel and Marini (1995) offered the explanation that fundamental gender differences existing in this observation. The researchers posit that women obtain satisfaction from social aspects of the jobs compared to men's obtaining satisfaction from advancement opportunities and pay. According to Beutel and Marini (1995), women tend to be more concerned with the well-being of others and therefore are less likely to be concerned with competiveness and materialism. Tolbert and Moen (1998) suggested that women exhibit a trend to place higher values on social aspects of the job and other intrinsic rewards. This would explain why women may gain more satisfaction from work that entails closer relationships with colleagues and a sense of accomplishment, rather than the higher pay and advancement opportunities. This is further supported by occupational sex segregations that finds women are more prominently represented in social-oriented occupations and men in achievement-oriented occupations (Glick \& Fiske, 2007). Men's focus on competition and materialism confirms findings by Phelan (1994) and better explains the paradox of the contented female worker.

Men who delay committed relationships or family should benefit in the domain of job satisfaction, because this would allow them to be more focused on the extrinsic benefits of their career. This could allow for added pressure for their female significant others to delay their career in order to focus more on household and family responsibilities. Tolbert and Moen (1998) observed national data spanning over 20 years, finding a pattern of men's gaining satisfaction from work and women's experiencing stress from work family conflict, resulting in men's and women's preferring differing careers. Men preferred careers allowing for greater pay and advancement and women preferred careers allowing for greater flexibility and social support. Meaningful work is women's preference, whereas men prefer promotion opportunities and job security (Tolbert \& Moen, 1998). Konrad, Corrigall, Lieb, and Ritchie (2000) conducted a meta-analysis finding women preferred more careers allowing for stereotypical preferences reflecting expressiveness and nurturing, while men preferred careers that allowed them to be the provider and successful.

Knowing the effects of work-life balance on major life decisions is important in understanding gender differences in organizational behavior. Aside from a better understanding, this would also provide valuable insight in how to restructure organizations to provide more benefits to both the organization and its members. Gender differences were hypothesized in the effects of delaying a career on job satisfaction as well as family stress. As job satisfaction is also related to life satisfaction (Judge, 1993), overall life satisfaction was examined. Overall, decisions to delay a romantic relationship and family should have a stronger effect on women's satisfaction levels than men's.

\section{Hypotheses}

\section{Hypothesis 1}

There will be a significant interaction between gender and delay of relationships on job satisfaction. Women should be more satisfied, if they have delayed family (reducing work family conflict) and men should be more satisfied when they do not delay family. 


\section{Hypothesis 2}

There will be a significant interaction between gender and delay of relationships on life satisfaction. Women should be more satisfied, if they have delayed family and men should be more satisfied when they do not delay family.

\section{Hypothesis 3}

There will be a significant interaction between gender and delay of relationships on focus on work. Women who delay family for work will be more focused on work than any other groups.

\section{Hypothesis 4}

There will be a significant interaction between gender and delay of relationships on work/family stress. Women should be less stressed, if they have delayed family and men should be less stressed, when they do not delay family.

\section{Methods}

Data were drawn from the 2002 NSCW (National Study of the Changing Workforce), a representative sample of American workers. This random sample was conducting using phone interviews of working adults. Multiple phone calls were made for each randomly selected phone number and a cash incentive was offered. The response rate was over $90 \%$. For the purpose of this study, only full-time salary workers were analyzed ( $N$ $=3,504)$. The sample was $44 \%$ male and 56\% female, and worked an average of 39.9 hours a week. Managers made up $42 \%$ of the sample. Across occupations, men earned more money $(M=\$ 60,306)$ than women $(M=$ \$34,716), $t_{(3272)}=7.712, p<0.001$.

The NSCW survey consists of approximately 600 items. For the purposes of this study, gender (male or female) and whether job pressures have delayed relationship commitment were used as independent variables. Family relationship delay was measured using a single item question asking participants to answer "Yes" or "No" whether they had delayed their romantic and/or family plans due to work. Dependent variables included life satisfaction, job satisfaction, focus on work and work/family stress. The dependent variables were single-item questions and were measured in Likert scales. Life satisfaction was measured on a four-point scale ranging from 1 (Very dissatisfied) to 4 (Very satisfied). Job satisfaction was measured using a four-point scale ranging from 1 (Not at all) to 4 (Very satisfied). Focus on work was measured on a five-point scale ranging from 1 (Family is more important than work) through 3 (Work and family are equally important) to 5 (Work is more important than family). Work/family stress was measured on a five-point scale ranging from 1 (Extremely stressful) to 5 (Not at all stressful).

\section{Results}

Hypotheses were analyzed using between subject ANOVAs. Each hypothesis was examined first using an ANCOVA to determine if salary differences between men and women had a significant effect on any of the planned analyses. Salary was not a significant covariate on any of the analyses and therefore ANOVAs using gender and delay of relationship, as the independent variables were used examining the four outcomes. Each analysis was examined for statistical assumptions which were met in each case.

\section{Hypothesis 1}

There was a significant interaction between gender and delaying relationship commitments on job 
satisfaction, $F_{(1,3481)}=6.86, p=0.009$ (see Figure 1). Men who had not delayed committing to a relationship were significantly more satisfied $(M=2.97)$ than men who had delayed committing to a relationship because of work $(M=2.65)$. There was not a significant difference between women who had delayed commitment $(M=$ $2.80)$ than those who had not delayed $(M=2.817), F_{(1,1934)}=0.02, p=0.90$. The decision to delaying family had a negative impact on men's job satisfaction, but did not affect women's job satisfaction. Hypothesis 1 was partially supported.

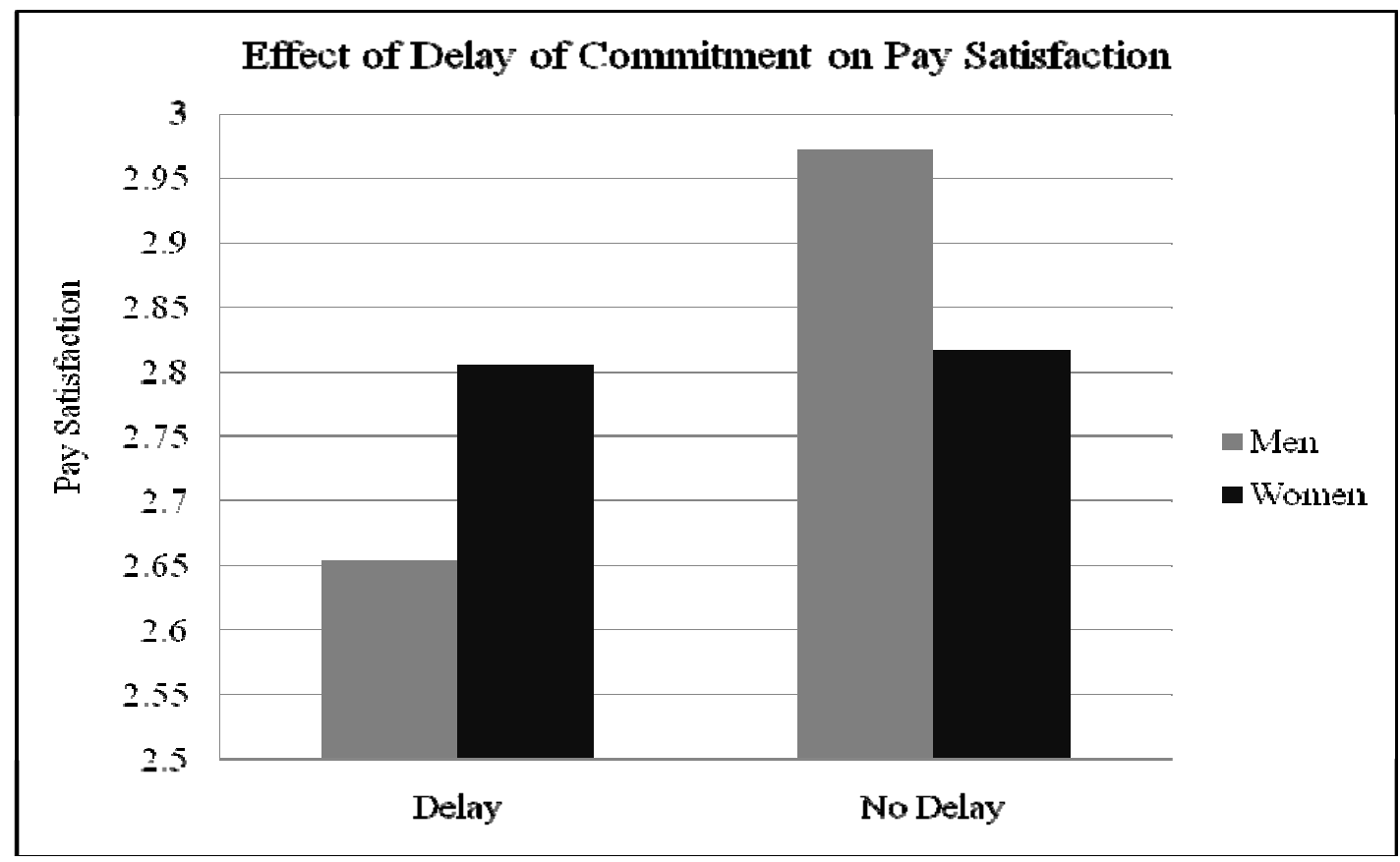

Figure 1. The interaction between career delay and gender on pay satisfaction.

\section{Hypothesis 2}

There was not a significant interaction between gender and delaying relationship commitments on life satisfaction, $F_{(1,3842)}=0.75, p=0.39$. There was not a main effect of gender on life satisfaction, $F_{(1,3482)}=0.02$, $p=0.88$. There was a main effect of delaying commitment on life satisfaction, $F_{(1,3482)}=32.89, p<0.001$, demonstrating that those who have delayed their committed relationships were significantly less satisfied $(M=$ 3.04) compared to those who have not delayed commitment because of work $(M=3.31)$. Men and women reported lower life satisfaction when they had delayed family for their career. Hypothesis 2 was not supported as both men and women reported lower levels of life satisfaction when they chose to delay family for their careers.

\section{Hypothesis 3}

There was a significant interaction between gender and delaying relationship commitments on focus on work, $F_{(1,2822)}=6.88, p=0.009$ (see Figure 2). Women who had delayed committing to a relationship were significantly more focused on work over family $(M=3.14)$ than women who had not delayed family $(M=2.45)$, men who had delayed family $(M=2.71)$ and men who had not delayed family $(M=2.55)$. Women who delayed family for career were significantly more focused on job over family than women who had not delayed family and men who had or had not delayed family for career. Hypothesis 3 was supported. 


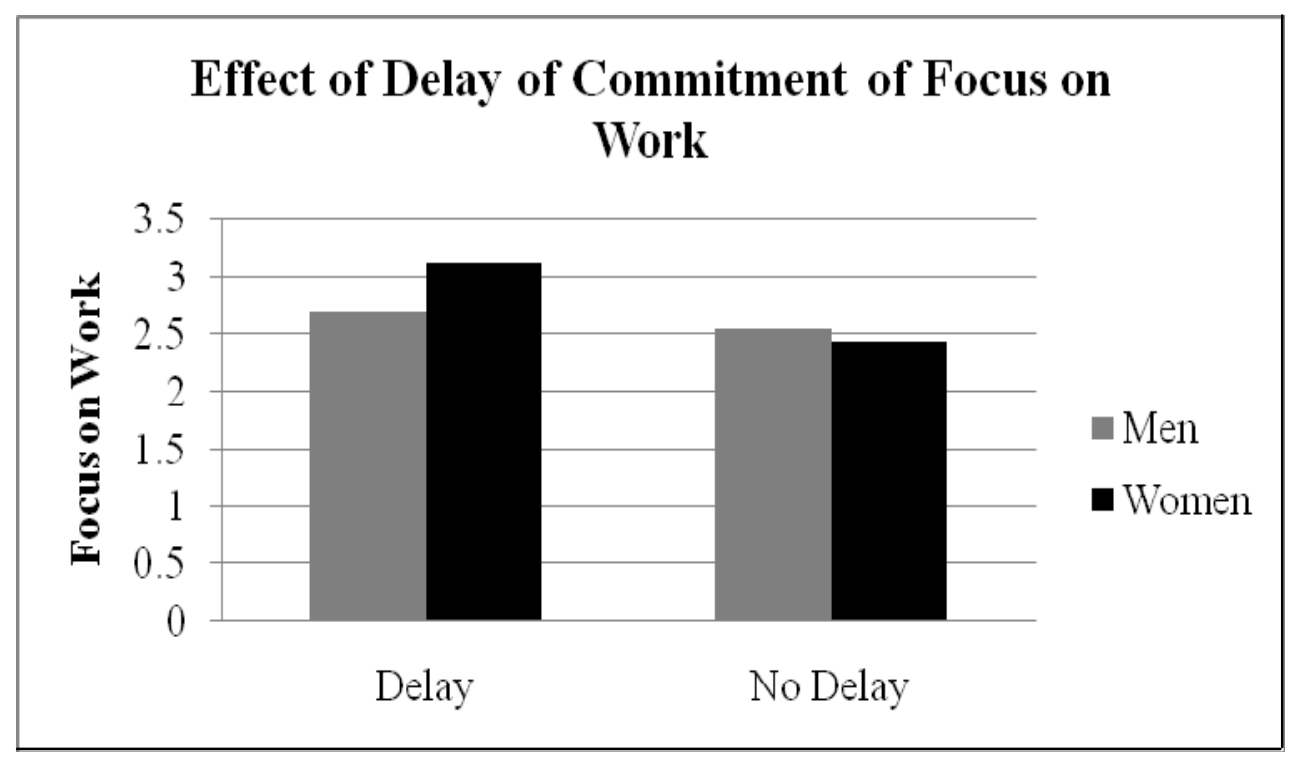

Figure 2. The interaction between career delay and gender on focus on work.

\section{Hypothesis 4}

There was not a significant interaction between gender and delaying relationship commitments on personal/family stress, $F_{(1,3490)}=0.23, p=0.61$. There was a main effect of gender on personal/family life stress, $F_{(1,3490)}=17.64, p<0.001$, as females were more likely to have experienced personal/family life stress ( $M=2.84)$ compared to males $(M=2.53)$. There was also a main effect of delaying commitment on personal/family life stress, $F_{(1,3490)}=19.32, p<0.001$, as individuals who delayed commitment reported more personal/family life stress $(M=2.84)$ than those who had not delayed commitment $(M=2.52)$. Hypothesis 4 was not supported as a gender by family delay interaction was not found. However, there were two main effects: Women reported more work/family stress compared to men and both men and women reported more work family stress when they decided to delay family for their careers.

\section{Discussion and Conclusions}

The decision to delay commitment did affect men's job satisfaction with men that delayed family reporting lower satisfaction with their current work. Women's job satisfaction was unaffected by a decision to delay family. Because women report higher job satisfaction than men to begin with, women may be focusing more on the social aspects of their job which tend to be not as affected by work-family balance as pay or advancement opportunities. Additionally, women tend to self-select into occupations that emphasize socialization over advancement, regardless of decisions to delay marriage and/or family commitments. This self-selection into occupations may be influencing the results, as women who report restriction, not unavailability, of advancement opportunities and pay may have different experiences with job satisfaction when delaying commitments than women who are in careers focus less on advancement. In other words, women who desire advancement in their career may be more satisfied after delaying commitments than those who are not as concerned with advancement. Additional studies may help examine this further.

Men and women did not differ on levels of life satisfaction. However, both men and women reported lower levels of life satisfaction when they had previously decided to delay family for their career. Women who 
chose to delay their careers reported a stronger focus on work over family than women who had not delayed family or men whether they had delayed family for careers or not. Finally, women in general reported more work-family stress, and both men and women who had delayed their family for their career reported more work-family stress. Taken together, the decision to delay family for work affects men and women differently and generally is not a successful strategy for reducing work-family stress, increasing job satisfaction or increasing life satisfaction. Men who did not delay family had higher job satisfaction, higher life satisfaction, and less work family stress. Women who did not delay family had higher life satisfaction and reported less work-family stress. There was also a significant difference between men and those who chose to delay their family for career and women reporting a stronger focus on work over family compared to men.

Women typically report lower earnings and fewer advancement opportunities compared to men. Additionally, women are feeling pressured to choose between their careers and committing to relationships and a family. Career-oriented women desiring a family may have to delay family and relationships to keep advancement opportunities available. Women that do not delay commitment to family find themselves trying to balance work and family responsibilities to a greater extent than men in a similar situation. This struggle to find a balance often leads to increased personal stress. Having someone to share these responsibilities helps these women perceive less stress in the home and devote more energy to their careers. However, men report greater flexibility and support compared to women in dual-income partnerships.

Women were found to earn less and yet be more satisfied with their jobs compared to men. Despite of lesser job titles and fewer advancement opportunities, women are more satisfied which demonstrates the paradox of the female contented worker (Buchanan, 2005). This remains even when the female owns the business and it is not as successful as a comparative male-owned business (Powell \& Eddleston, 2007). As it is consistent with current trends, males surpassed females in salary amounts, though caution must be used in interpreting these data. Explanatory factors that could influence pay amounts were not accounted for in this study.

One factor to be considered is the impact that delaying family life can have on job satisfaction as women's career expectations for progression are increasing. Men report positive impact of delaying family commitment while women see no such improvement. One explanation for this could be that women tend to be more satisfied by intrinsic rewards than men (Tolbert \& Moen, 1998) and delaying a family commitment may allow men to be more focused on extrinsic rewards, such as higher pay or advancement opportunities without having to worry about balancing work and family responsibilities, when they have a significant other in the home to take on household responsibilities.

It would seem to make sense that delaying a committed relationship or postponing having children would make life easier for anyone, especially women. Not having to worry about small children, less household chores and more resources devoted to one's career seem like good reasons to delay family life for women. However, this research indicates that those who do not delay relationships and family tend to experience significantly more satisfaction with life. One explanation for this could be the support provided by one's family. In a study to build a more complete working model of work-family conflict, Carlson and Perrewé (1999) stated that "Social support may reduce perceived role stressors and time demands, and thus, indirectly decreases work-family conflict”. Ford et al. (2007) examined contributors to stress and support specific from family and work domains and found that they were actually influential across domains as well. These examples support our findings that delaying a committed relationship could lead to lower life satisfaction because of lower levels 
of support from one's family to spill over into the work domain.

Limitations of the current research include no available measurement of individual difference variables, such as personality, self-efficacy, motivation, or gender role orientation. Additionally, the data presented is cross sectional, participants reported on past decisions to delay their family and current levels of satisfaction. Although, our study did find gender differences in the effects of delaying family for career on the outcomes and these differences may also reflect differences in career choices and job commitment. Due to the nature of this study, no causal conclusions can be made.

Opportunities for future research include the possibility of measuring egalitarian beliefs, as there is some evidences that cultures high in egalitarian gender roles may have an effect on the way men and women are rated for advancement potential and the distribution of household chores and familial obligations. Another area of research to pursue should be how external variables, such as the increasing number of single parents and economic downturns are influencing satisfaction along these three measures. Additionally, longitudinal studies would allow for a stronger causal examination tracking choices favoring work over family over time and the subsequent possible effects on job and life satisfaction.

Overall, the decision to delay relationships or family can impact a person's job and life satisfaction and work-family balance in different ways. Making the decision to balance both family and a forward-progressing career can increase feelings of imbalance for both sexes, but impacts women more. Even with additional partner support, women still report feeling stressed about the balance between work and family. Additionally, women may be self-selecting into careers that do not require as much family renegotiation and thus less advancement. Although work-life family balance can be impacted by work demands, individuals with a family report higher life satisfaction. Though having a family may be stressful, it appears the social support that family creates mitigates some of the stress created by it! Achieving work-life balance, making the decision to delay relationship and family and job and life satisfaction can all be affected by, and in turn effect, many different variables. The prerogative, then, is to continue to study and learn about these differences so that work balance and family decisions can be positively impacted. Both employees and organizations have the opportunity to benefit from continued research in this area.

\section{References}

Baldridge, D. C., Eddleston, K. A., \& Veiga, J. F. (2006). Saying no to being uprooted: The impact of family and gender on willingness to relocate. Journal of Occupational and Organizational Psychology, 79, 131-149.

Beutel, A. M., \& Marini, M. M. (1995). Gender and values. American Sociological Review, 60(3), 436-448.

Bond, J. T., Thompson, C., Galinsky, E., \& Prottas, D. (2002). Highlights of the national study of the changing workforce. New York, N. Y.: Families and Work Institute.

Buchanan, T. (2005). The paradox of the contented female worker in a traditionally female industry. Sociological Spectrum, 25(6), 677-713.

Buddhapriya, S. (2009). Work-family challenges and their impact on career decisions: A study of Indian women professionals. The Journal of Decision Makers, 34, 34-45.

Canivet, C., Östergren, P., Lindeberg, S., Choi, B., Karasek, R., Moghaddassi, M., \& Isacsson, S. (2010). Conflict between the work and family domains and exhaustion among vocationally active men and women. Social Science and Medicine, 70, 1237-1245.

Carlson, D. S., \& Perrewé, P. L. (1999). The role of social support in the stressor-strain relationship: An examination of work-family conflict. Journal of Management, 25(4), 513-540.

Drobnic, S., Blossfeld, H., \& Rohwer, G. (1999). Dynamics of women's employment patterns over the family life course: A comparison of the United States and Germany. Journal of Marriage and the Family, 61, 133-146. 
Eagly, A. H. (1987). Sex differences in social behavior: A social-role interpretation. Hillsdale, N. J.: Erlbaum.

Escriche, L. (2007). Persistence of occupational segregation: The role of the intergenerational transmission of preferences. The Economic Journal, 117, 837-857.

Ford, M. T., Heinen, B. A., \& Langkamer, K. L. (2007). Work and family satisfaction and conflict: A meta-analysis of cross-domain relations. Journal of Applied Psychology, 91, 57-80.

Galakanis, M., Salikas, A., Kallia, H., Karagianni, C., \& Karela, C. (2009). Gender differences in experiencing occupational stress: The role of age, education and marital status. Stress and Health: Journal of the International Society for the Investigation of Stress, 25, 397-404.

Glick, P., \& Fiske, S. T. (2007). Sex discrimination: The psychological approach. In F. J. Crosby, M. S. Stockdale, \& S. A. Ropp (Eds.), Sex discrimination in the workplace (pp. 155-188). Malden, M. A.: Blackwell.

Hoffnung, M. (2004).Wanting it all: Career, marriage, and motherhood during college-educated women's 20s. Sex Roles, 50, 711-723.

Hough, J. R. (1987). Education and the national economy. New York: Croom Helm.

Judge, T. A. (1993). Another look at the job satisfaction-life satisfaction relationship. Journal of Applied Psychology, 78, 939-948.

Kaufman, G., \& Uhlenberg, P. (2000). The influence of parenthood on the work effort of married men and women. Social Forces, 78, 931-949.

Konrad, A. M., Corrigall, E., Lieb, P., \& Ritchie, J. E. (2000). Sex differences in job attribute preferences among managers and business students. Group and Organization Management, 25(2), 108-131.

Morgan, L. A. (2008). Major matters: A comparison of the within-major gender pay gap across college majors for early-career graduates. Industrial Relations, 47, 625-650.

Nielsen, K., Yarker, J., Randall, R., \& Munir, F. (2009). The mediating effects of team and self-efficacy on the relationship between transformational leadership, and job satisfaction and psychological well-being in healthcare professionals: A cross-sectional questionnaire survey. International Journal of Nursing Studies, 46, 1236-1244.

Perrachione, B. A., Rosser, V. J., \& Peterson, G. J. (2008). Why do they stay? Elementary teachers' perceptions of job satisfaction and retention. Professional Educator, 32, 25-41.

Phelan, J. (1994). The paradox of the contented female worker: An assessment of alternative explanations. Social Psychology Quarterly, 57(2), 95-107.

Powell, G. N., \& Eddleston, K. A. (2007). The paradox of the contented female business owner. Journal of Vocational Behavior, 73, 24-36.

Presser, H. B. (1994). Employment schedules among dual-earner spouses and the division of household labor by gender. American Sociological Review, 59, 348-364.

Sewell, W. H., Hauser, R. M., \& Wolf, W. C. (1980). Sex, schooling, and occupational status. American Journal of Sociology, 86, 551-583.

Tolbert, P. S., \& Moen, P. (1998). Men’s and women’s definitions of “good” jobs: Similarities and differences by age and across time. Work \& Occupations, 25, 168-194.

Vagg, P. R., Spielberger, C. D., \& Wasala, C. F. (2002). Effects of organizational level and gender on stress in the workplace. International Journal of Stress Management, 9, 243-261.

Whitmarsh, L., Brown, D., Cooper, J., Hawkins-Rodgers, Y., \& Wentworth, D. (2007). Choices and challenges: A qualitative exploration of professional women's career patterns. The Career Development Quarterly, 55(3), 225-236. 